\title{
El manejo de los restos de humanos y animales: una reflexión en torno a las nociones ontológicas lacandonas
}

\author{
The disposal of human and animal remains: \\ A discussion concerning the Lacandon ontological notions
}

Alice Balsanelli

doi.org/10.29043/liminar.v20i2.910

Resumen: En este escrito se plantea una discusión en torno al concepto de "persona" elaborado por los lacandones del norte en Chiapas, México, quienes reconocen que todo lo existente está dotado de alma (pixan), por ello, los seres que habitan la selva, incluyendo los animales, se consideran personas (winik) en esencia. Así, en un sistema en el que todo es intrínsecamente "persona", los lacandones recurren a las diferentes fisicalidades para clasificar la alteridad y definirse como grupo étnico. A través del análisis del tratamiento funerario destinado a los diferentes winik, se ilustrarán las nociones ontológicas del grupo lacandón. Se demostrará que los conceptos "persona", "humanidad" y "animalidad" son relativos y culturalmente variables.

Palabras clave: lacandones, concepto de persona, alma, alteridad, ritos funerarios, restos humanos.

Abstract: The essay examines the notion of personhood among Northern Lacandon people in Chiapas, Mexico. The Lacandon believe that everything that exists is endowed with a soul (pixan); therefore, all creatures inhabiting the jungle, including animals, are regarded in essence as people (winik). Thus, in a system where everything is intrinsically "human", the Lacandon resort to different physicalities to classify otherness and define themselves as an ethnic group. We illustrate the ontological conceptions of the Lacandon through the analysis of the burial treatment given to the different winik. We show that concepts such as "personhood", "humanity," and "animality" are relative and culturally variable.

Key words: Lacandon Maya, personhood, soul, otherness, mortuary rites, human remains.

* Becaria del programa de Becas Posdoctorales UNAM, Centro de Estudios Mayas, Instituto de Investigaciones Filológicas, Universidad Nacional Autónoma de México, México alice.balsanelli@yahoo.com (iD) 0000-0002-4785-5554 


\section{Introducción y metodología}

$\mathrm{E}$ n el presente escrito se analiza la manera en la cual los lacandones o Hach Winik (hombres verdaderos) destinan diferentes tratamientos funerarios a los distintos seres que habitan en su entorno. Se desea demostrar que lo anterior deriva de una peculiar concepción de persona elaborada por el grupo lacandón de acuerdo con sus nociones ontológicas, la cual influye en el comportamiento de los hombres hacia los demás sujetos que los rodean. Se emplea la expresión "clasificación ontológica" en la acepción propuesta por Descola (2012), quien la define como un método de clasificación de lo existente, culturalmente variable, y que en las sociedades nativas difiere de la taxonomía occidental dictada por parámetros científicos modernos. En este sentido, en Occidente la idea de persona adquiere una significación unívoca y universal, y lo humano corresponde únicamente a la especie Homo sapiens, es decir, al hombre y la mujer. Por el contrario, las sociedades indígenas pueden extender la condición de humanidad a un colectivo más amplio, incluyendo a los animales, las plantas, los espíritus e incluso a unos cuantos elementos inertes (Descola, 2012). En estos contextos, la condición de humanidad es una cualidad intrínseca; no es una característica biológica o física, sino anímica y, por lo tanto, latente, mientras que los cuerpos representan el elemento variable. Así, se recurre a las distintas fisicalidades para marcar las diferencias ontológicas (Vilaça, 2014, p. 325; Viveiros, 2010, p. 50). Como aclara Viveiros de Castro, el cosmos amerindio está habitado por diferentes especies de sujetos o personas, humanas y no humanas, que poseen agencia y que, por consiguiente, se consideran sujetos. En estos contextos, el término "gente" o "persona" no indica la pertenencia a la especie humana, sino una condición común a todos los seres del cosmos, dotados de la misma entidad anímica, pero diferentes en sus fisicalidades (Viveiros, 1996, pp. 125-126).

En la cultura lacandona, esta peculiar noción de persona se conceptualiza en el término winik (gente), empleado para los animales, las plantas, los espíritus, los dueños de los animales, los elementos naturales y algunos enseres rituales. Por mencionar un ejemplo, un lacandón sabe que los animales viven en la selva, en sus aldeas, y que además están socialmente organizados, poseen una cultura material y hasta un sistema religioso (Roblero, 2008), aunque a los ojos de los Hach Winik aparezcan como pecarís, monos o venados. Este concepto delinea una condición de humanidad generalizada y fue observado también entre los antiguos mayas: "los mayas clásicos categorizaban distintos seres bajo el término winik, 'persona', pero quizá este encierra el significado más genérico de 'dotado de alma, ser consciente. Había muchos géneros de winik, también sobrenaturales" (Houston, Stuart y Taube, 2006, p. 11, traducción propia). La misma idea está presente en numerosas sociedades mayas contemporáneas, en donde se piensa que los animales son seres conscientes y organizados en grupos sociales (Anderson y Tzuc, 2005, xi, p. 38; Estrada, 2009, p. 198; Thompson, 1982, pp. 208-209). De este modo, en un cosmos poblado por numerosas subjetividades, hombres y mujeres necesitan diferenciarse de la "humanidad genérica" a su alrededor (Vilaça, 2002; 2014). Así, cada sociedad establece sus propias taxonomías y reivindica su singularidad elaborando nociones de pertenencia a un determinado grupo étnico. Por ejemplo, los lacandones reconocen que las plantas, los animales y los espíritus son gente en esencia (winik), pero ellos se asumen como la Gente Verdadera (Hach Winik), los únicos "hombres auténticos". En este caso, el término Hach Winik se emplea como etnónimo, designando así a los miembros de un específico grupo social y cultural. En palabras de un interlocutor: "Hach Winik somos maya, la gente verdadera, que 
habla jach tan [la verdadera lengua], tenemos túnica y cabello largo, comemos de la milpa, puro maíz y frijol, somos la gente de la selva" (don K., Metzabok, comunicación personal, 20 de diciembre de 2020).

En los contextos indígenas, la condición de persona no es dada, sino que se construye paulatinamente al interior del contexto social (Vilaça, 2002), pues el alma representa el elemento innato e inmutable, mientras que el cuerpo está sujeto a modificaciones y permite identificar la alteridad, así como organizarla en categorías (Viveiros, 2010, pp. 30-38). Pitarch (2000), quien estudia a los mayas tseltales, confirma que en un cosmos poblado por distintas "personas", la especificidad de los seres humanos reside en el cuerpo, es decir, el elemento que se construye a lo largo de la vida del sujeto. Al respecto, este autor puntualiza lo siguiente:

Aquello que otorga a la persona su condición propiamente humana es el cuerpo. Las almas nada tienen de específicamente humano, pertenecen al mundo de los animales, de los espíritus y de otros fenómenos naturales. O de manera más precisa, las almas son estos seres. En cambio, es el cuerpo humano el que pliega el afuera y el pasado, el que produce un aquí y un ahora, que confiere una condición característica a los hombres (Pitarch, 2000, p. 7).

En el presente escrito se analizará la manera en la cual los cuerpos de los distintos seres del cosmos son tratados después de la muerte, esto de acuerdo con las clasificaciones ontológicas lacandonas. Se empezará por una introducción inherente a los ritos funerarios, haciendo referencia a los autores que se dedicaron al estudio de este tema (Baer y Baer, 1950; Boremanse, 2020; Bruce, 1974; Marion, 1999, entre otros) y, posteriormente, se examinará el manejo de los restos de los animales silvestres. Puesto que no se dispone de datos consistentes relativos a dicho tema debido a que los aspectos rituales de la cacería lacandona no han sido estudiados de manera exclusiva en otras obras etnográficas, se emplearán, principalmente, los datos de campo. Anticipamos que, por lo general, los seres humanos necesitan de un entierro y de un rito funerario específico, mientras que los despojos de los animales deben depositarse en el interior de los troncos de los árboles o en las cavidades naturales. No obstante, en campo se observaron algunas excepciones, por ejemplo, animales que deben enterrarse y "humanos" cuyos restos se devuelven a la selva. El estudio de estos casos peculiares permitirá reflexionar sobre la noción de persona elaborada por el grupo lacandón.

El trabajo de campo se realizó entre los lacandones del norte, ${ }^{1}$ asentados en las comunidades de Nahá y Metzabok, municipio de Ocosingo, Chiapas, en el noroeste de la Selva Lacandona. La investigación etnográfica en las comunidades mencionadas empezó en el año 2011, y sigue hasta la fecha [2021]. La constante convivencia con los lacandones, durante largas temporadas - de un mínimo de dos meses hasta un año-, aunado al aprendizaje del idioma nativo (el maya lacandón del norte), constituyeron el método principal para la recolección de los datos empíricos. La posibilidad de conversar en lengua maya permitió realizar entrevistas extensas, incluyendo a aquellos interlocutores que no podían expresarse en español. Finalmente, los datos recabados en campo se interpretaron con el apoyo de la información etnográfica relativa a otros estudios realizados en el área maya y en otros contextos geográficos.

\footnotetext{
${ }^{1}$ En los estudios antropológicos se suele distinguir entre el grupo norte y el grupo sur, que se tratan como dos realidades sociales distintas puesto que presentan diferencias en el idioma, en la vestimenta y en la cosmovisión (Boremanse, 1984, pp. 226-227).
} 


\section{El destino de los Hombres Verdaderos}

El ser humano lacandón está dotado de dos entidades anímicas principales: el pixan —el alma-corazón, el cual se encuentra en el músculo cardíaco, en las venas y en las sienes-(Boremanse, 1998a, p. 91), y el kisin 'ok' (espíritu del pie o de la mano), el cual se ubica en el esqueleto (Baer y Baer, 1950, p. 221). Cuando fallece la persona, el pixan abandona el plano terrenal y empieza un largo recorrido que lo llevará hasta su destino final. Numerosos autores han analizado el destino post mortem del pixan, así como los ritos funerarios (Boremanse, 1998a, 2020; Bruce, Roberto y Ramos, 1971; Kováć, 2016; Marion, 1999; McGee, 1990). A continuación, se expone un resumen en el que se mencionan las fuentes en orden cronológico.

El primer antropólogo que describe los ritos funerarios lacandones es Tozzer (1907, pp. 63-64), quien reporta que en la comunidad lacandona se sostenía que las dos principales fuerzas anímicas tenían dos distintos destinos finales: el "pulso" descendía al inframundo para vivir con Kisin, el Causante de la Muerte, y el corazón ascendía con la finalidad de morar con las deidades celestes. De acuerdo con Soustelle (1959, p. 156), la mayoría de los lacandones relataba que, después de la muerte, las almas subían al cielo, en donde se establecían en viviendas idénticas a las utilizadas en el mundo terrenal. Soustelle no menciona el inframundo como destino final.

En palabras de Bruce (Bruce, Robles, Ramos, 1971: 118), el destino de ultratumba de las almas lacandonas es el bajo mundo, el cual se divide en dos reinos; el primero se llama U Yalam Lu'um (literalmente "bajo mundo"), y queda bajo el dominio del dios Sukunkyum, "El hermano Mayor de Nuestro Señor", quien desempeña el papel de juez de las almas. El segundo se llama Metlan (palabra náhuatl que significa "lugar de la muerte"), regido por el malvado Kisin, quien retiene las almas de las personas que no mantuvieron un comportamiento correcto en vida y las convierte en animales domésticos para atormentarlos y explotarlos a su antojo (Boremanse, 2006, pp. 78-79, 93-98). De acuerdo con la concepción del grupo del norte, cuando la persona muere, el alma baja al inframundo, en donde debe superar tres pruebas; la primera consiste en cruzar un río infestado de lagartos, con la ayuda de un perro, al cual el alma debe entregarle un hueso para convencerlo de que la transporte hasta la otra orilla. Luego, en la segunda prueba debe superar una barrera de piojos a los cuales el alma dona un mechón de cabello con el fin de pedirles que cedan el paso. Finalmente, esta se enfrenta a una multitud de pollos; el alma los alimentará con unos granos de maíz y podrá proseguir. Por esta razón, se colocaban en las manos del difunto un hueso largo, un mechón de su cabello y algunos granos de maíz (Bruce, 1974). Después de haber superado los obstáculos mencionados, el alma se presenta ante el juez supremo del bajo mundo, Sukunkyum, quien, mirándola a los ojos, lee en su mente qué faltas ha cometido en el transcurso de su vida terrenal. Las almas de aquellos que cometieron faltas menores pueden volver a la superficie y vuelan hacia la cueva del dios Mensabäk, en donde se reúnen con sus parientes difuntos y con sus ancestros. ${ }^{2}$ Por el contrario, quienes han cometido pecados graves son entregados a Kisin; el "demonio" tortura el

\footnotetext{
${ }^{2}$ La cueva se encuentra en la orilla de uno de los lagos de Metzabok y fue empleada como osario por los grupos mayas que antecedieron a los lacandones en la selva. La deidad que en ella mora, Mensabäk, además de ser el protector de las almas, es el dios de la lluvia.
} 
alma con hierros calientes, con el fuego y con agua helada, hasta convertirla en un animal doméstico (una vaca, un puerco, un ave de corral) que vivirá para siempre en sus corrales. Desde la época de las investigaciones de Bruce no se registran cambios significativos en las concepciones lacandonas, por ello, en las investigaciones contemporáneas se reportan los mismos conceptos acerca del destino final de las almas (Boremanse, 2020; Kováč, 2016; Marion, 1999).

Los lacandones piensan que durante los primeros días después del fallecimiento la persona no está consciente de haber muerto; así, el alma volverá a su casa, irá a la milpa a trabajar o buscará a sus familiares y amigos como solía hacerlo en vida. Durante esta fase, el pixan toma la apariencia de un "espectro", al cual los interlocutores describen como una entidad etérea, incapaz de hablar o de comunicarse. Quienes reciben una visita de esta entidad pueden enfermar y, a su vez, llegar a morir. En caso de que una persona no pueda recibir un entierro, esta condición liminar del pixan se vuelve permanente y el alma será condenada a vagar por el pueblo o por la selva para siempre. Esta creencia encuentra varios correspondientes en otros grupos mayas, pues se difunde la idea de que el alma del recién fallecido representa una amenaza para los vivos; en cuanto el difunto aún no se haya dado cuenta de su nueva condición, no aceptará abandonar la tierra, o bien sentirá el deseo de llevar consigo a sus seres queridos. También se consideran perjudiciales su vivienda, sus pertenencias y sus despojos, ya que pueden retener parte de la fuerza anímica de su dueño (Guiteras, 1965, p. 130; Petrich, 2007, p. 150; Pitarch, 2013, pp. 23-24). De este modo, los ritos funerarios tienen la finalidad de permitir al alma inmortal abandonar el mundo terrenal y llegar en paz a su destino final; esto también asegura la incolumidad de "los que se quedan". En el grupo lacandón, el cuerpo del difunto o de la difunta debe velarse durante tres días, el tiempo necesario para convencer al alma de abandonar el mundo terrenal. Aún se registra la costumbre de realizar pequeños perritos de hoja de palma, los cuales protegen al alma durante su tránsito en el bajo mundo (Tozzer, 1907, pp. 63-64). Estos se depositan en la tumba, se encienden velas para alumbrar el camino del alma y se dejan ofrendas para alimentarla: tortillas, pozol, refrescos u otros alimentos que la persona solía consumir en vida (ver Imagen 1). A pesar de que la mayoría de la gente de Nahá y Metzabok afirme haberse adherido a la religión cristiana, el rito funerario sigue llevándose a cabo según dicta la antigua costumbre. Los pastores reiteran constantemente que los parientes del difunto no deben llevarle comida porque, de acuerdo con su religión, las almas de los finados abandonan inmediatamente la tierra y volverán únicamente el día del Juicio Universal. También, se critica la costumbre de realizar los perros de hoja de palma y de encender velas, las cuales los religiosos definen como "idolatría". No obstante, durante los últimos entierros — de 2018 a 2020 - se observó que no se ha abandonado la costumbre de realizar los perritos con hojas de palma y de entregar las ofrendas al difunto.

El rito funerario lacandón parece representar la última resistencia ante el disgregamiento del complejo ritual, causado por la pérdida de los sabios expertos en los rituales (toohil), las conversiones masivas y lo que Marion, ya hace unas décadas, definió como "los efectos realmente desastrosos de la predicación evangélica" (1991, p. 107). Cuando se pregunta a los Hach Winik por qué siguen celebrando el rito funerario a pesar de las indicaciones de sus pastores, aclaran que se trata de una medida necesaria para que el alma llegue a su destino final y, así, no quede en la tierra para dañar a los demás:

Todo Hach Winik hay que enterrarlo. Si no entierras y no alimentas, su espíritu va caminando porque nadie lo enterró. Ya no es persona, es sombra, es puro kisin. Si lo encuentras, te espanta y te puede causar calentura. Si, pongamos, uno se pierde en la selva y allí muere, y nadie puede enterrar[lo], 
entonces no se puede ir, se queda como fantasma enojado, y viene por ti (doña T., comunicación personal, Nahá, diciembre de 2020).

Imagen 1. Perritos hechos con hoja de palma y velas depositados en una tumba durante un funeral, Nahá, 2018

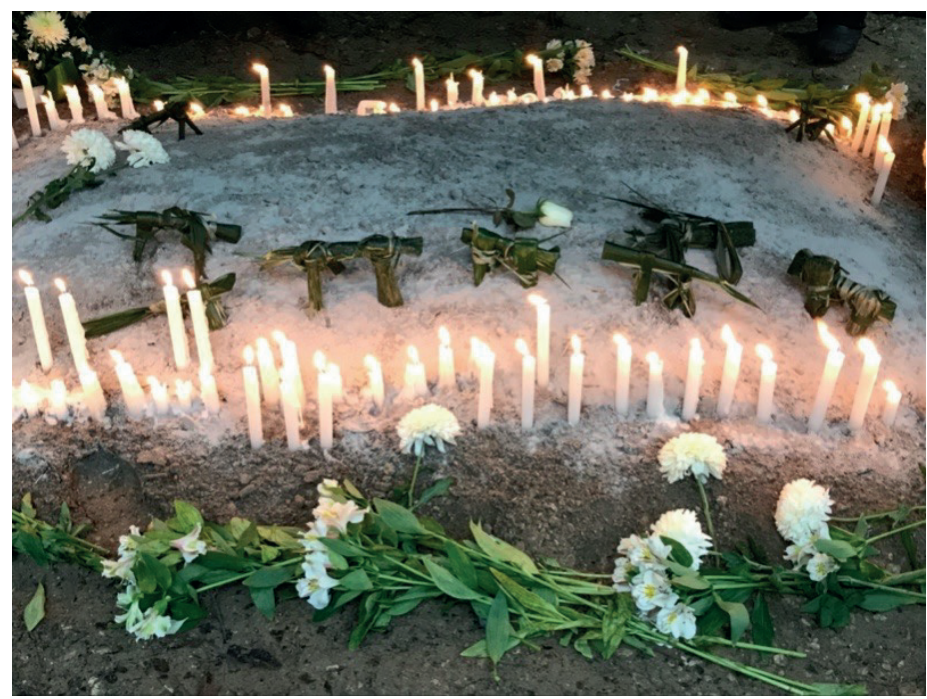

Fuente: foto de la autora.

\section{El cuerpo de las presas}

Puesto que los animales también se consideran dotados de alma (pixan), al morirse se orientan hacia un destino ultraterreno. Se piensa que las almas de los animales silvestres habitarán los bosques del inframundo, en donde serán inmunes a las flechas de los cazadores (Bruce, Roberto y Ramos, 1971, p. 126). Se cree que cuando este mundo sea destruido por los dioses, durante el X'ur T'an (el Fin del Mundo), las almas de todas las criaturas silvestres volverán a la tierra para reunirse con sus restos mortales y nacerá así una nueva generación de humanos y animales. De este modo, así como las personas deben enterrarse, es necesario preservar los huesos de las presas para permitir su resurrección (Boremanse, 2006, p. 100). Esta idea puede haberse originado después de la penetración de los conceptos cristianos acerca del destino final de los seres humanos; no obstante, cabe señalar que, entre los antiguos mayas, los huesos se consideraban elementos fértiles portadores de las instancias anímicas de los difuntos. Así, los despojos de los ancestros, de los personajes de relieve o de los cautivos eran sujetos a diversos tratamientos rituales, con la finalidad de preservar las propiedades vitales en ellos contenidas (Fitzsimmons, 2009, pp. 167-168; Scherer, 2015, pp. 94-95). De este modo, se puede inferir que la concepción lacandona relativa a la conservación de los restos de las presas se originó de la fusión de las nociones de los mayas antiguos con aquellas introducidas por las nuevas religiones.

Antiguamente, los restos de las presas se depositaban en la selva, en el interior de los troncos de grandes árboles, o bien en las cavidades naturales. Aunque ya no se lleve a cabo el depósito ritual de los 
restos, se observa que ningún lacandón quema los huesos de las presas; estos se conservan en las repisas de la cocina o en otros espacios de las viviendas ${ }^{3}$ (ver Imagen 2).

Imagen 2. Los huesos de animales silvestres se conservan en las repisas de las cocinas después de haber consumido la carne. Metzabok, 2019

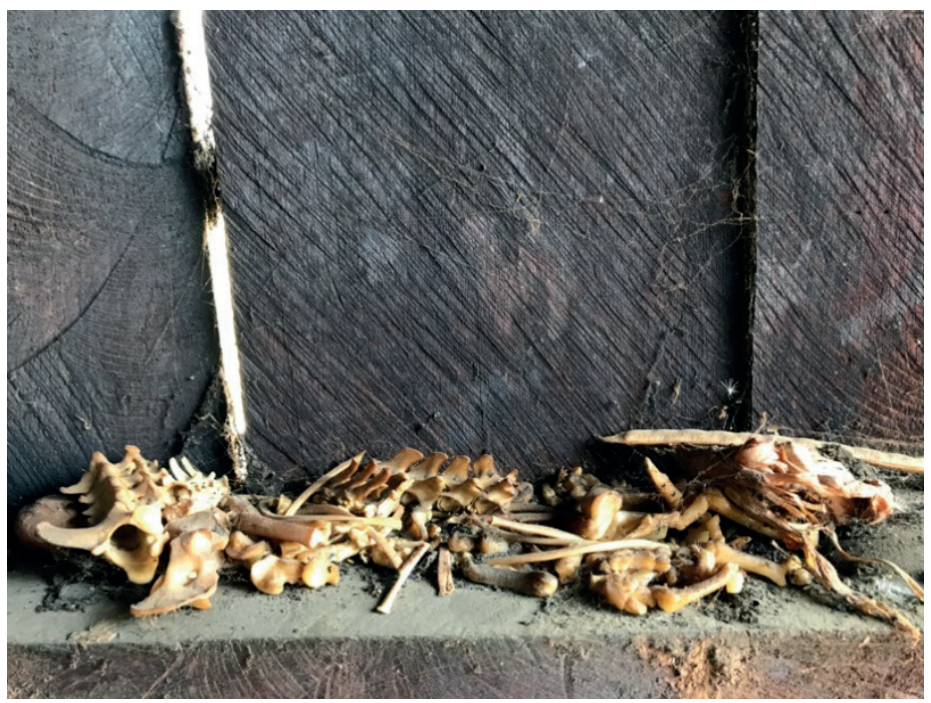

Fuente: foto de la autora.

Los animales son protegidos por algunas deidades terrenales, por ejemplo, Yajaw Ná (la Grande Casa), los Chembel K’uh (los Dioses Errantes o Menores) y K’änänk’ax (El que Cuida la Selva). La fauna también se encuentra bajo el cuidado de los dueños de las distintas especies: el dueño de los jabalís, el de los monos y el de los zopilotes, por mencionar algunos ejemplos (Boremanse, 2006). Estas entidades moran en la selva, en particular en las cuevas (Boremanse, 1998a, p. 27; 1998b, pp. 201-202), razón por la cual los restos de sus protegidos no pueden enterrarse y deben ser depositados en las "viviendas de los dueños". En diversos pueblos mesoamericanos y mayas se registra la misma concepción: se piensa que los dueños de la fauna habitan en las cavidades naturales del monte, y los restos de la caza deben depositarse en dichos lugares sagrados para que los dueños puedan regenerar a los animales sacrificados a partir de sus despojos (Brown y Emery, 2008; Dehouve, 2008; Osorio-López et al., 2017).

Asimismo, los Hach Winik aclaran que está prohibido quemar las espinas de los pescados. De acuerdo con algunos habitantes de Metzabok, en el pasado los restos de los peces y los caparazones de

\footnotetext{
${ }^{3}$ En el pasado, la caza se consideraba un importante medio de subsistencia en la comunidad lacandona (Baer y Merrifield, 1972; Soustelle, 1966; Tozzer, 1907). Entre las presas principales se encontraban el saraguato (Alouatta pigra), el pecarí (Tayassu pecarí), el cerdo de monte (Tayassu tajacu) y el hocofaisán (Crax rubra). La carne constituía asimismo una ofrenda ritual de gran importancia y la cacería implicaba un complejo ritual basado en la relación de reciprocidad entre los dueños de la fauna y las deidades protectoras de la selva y los cazadores. Sin embargo, a partir del año 1998, el área que ocupan hoy los lacandones se declaró bajo la categoría de Área de Protección de Flora y Fauna. Se prohibió la cacería en la selva, mientras que se sigue practicando de manera esporádica y controlada al interior de las milpas: se considera lícito matar a los animales que amenazan los cultivos. Por lo general, se trata de pequeños mamíferos. No obstante, en campo se observó que aún se conservan los restos de las presas.
} 
las tortugas se arrojaban a la laguna, pues sus dueños moran en el agua. En particular, se considera que el dueño de la fauna acuática, quien otorga el permiso para pescar, es Chäk Xoc (Boremanse, 2006, pp. 246-256). Este se presenta como una persona lacandona, viste la característica túnica de algodón blanco y lleva el cabello largo, pero la mitad inferior de su cuerpo termina en una cola de pez o de cocodrilo. Del mismo modo, uno de los peñascos presentes en la laguna de Metzabok es Ku'i Ak (el Dios de las Tortugas); de acuerdo con informantes locales, quienes deseaban alimentarse de carne de tortuga (ak) debían quemar copal en la cueva presente en el sitio para pedirle su permiso al dios y, posteriormente, debían depositar en su interior los caparazones vacíos (diario de campo, Metzabok, enero de 2021, ver Imagen 3). El depósito de los restos de peces en los cuerpos de agua se observa en numerosas sociedades, en donde la pesca constituye un recurso primario, volviéndose así una actividad ritual (Frazer, 1944, p. 596; Lot-Falck, 2018, p. 187).

Imagen 3. Un caparazón de tortuga depositado en la cueva de Chaachi'. Metzabok, 2017

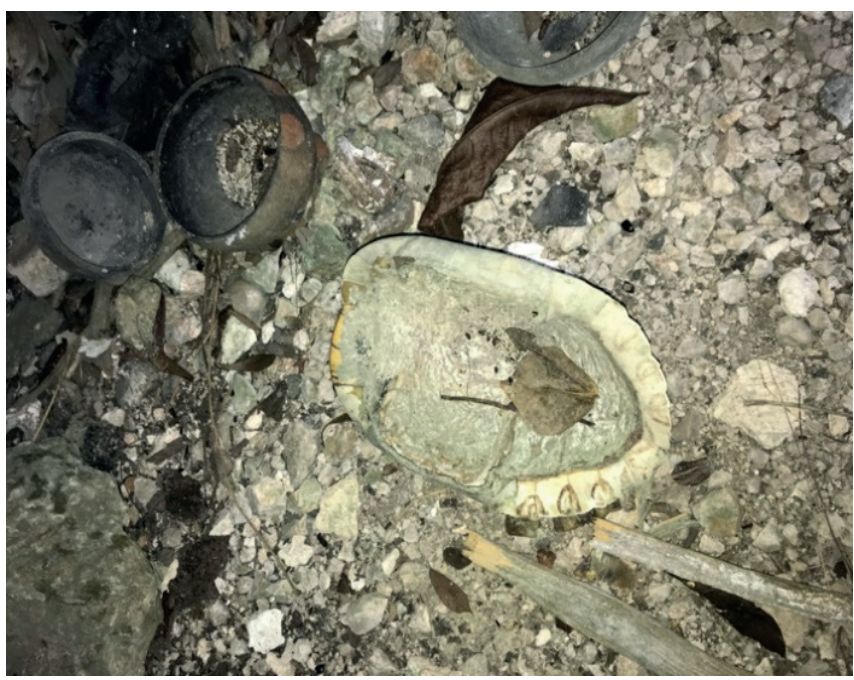

Fuente: foto de la autora.

En el mismo lugar, se encuentran huesos humanos e incensarios pertenecientes a antiguos to'ohil lacandones (expertos en rituales).

Quien no cumpla con la correcta devolución de los restos de las presas se enfrentará a algún castigo (Århem, 1996, p. 192; Anderson y Tzuc, 2005, p. 73; Cayón, 2012, p. 42; Dehouve, 2008, p. 11), ya que puede perder la facultad de cazar o pescar, o bien perderá a uno de sus animales domésticos, por ejemplo, un perro de cacería. Los dueños ofendidos también pueden cobrar la vida del cazador o de uno de sus familiares. Los lacandones subrayan que, a diferencia de lo prescrito para los seres humanos, enterrar a un animal representaría una grave falta.

Antes [los huesos] se llevaban a la selva, ahora ya no, pero los respetas, los guardas, y si los metes en la tierra, te van a castigar sus dueños. No puedes meterlos en la tierra, no puedes enterrar. $\mathrm{Si}$, pongamos, ves a un animal muerto en la selva, no lo puedes enterrar. Así como nuestro dios quiere que, si muero, 
me metan en el panteón, con las ofrendas y todo, porque así el pixan puede irse tranquilo, también los animales tienen su dios, tienen sus dueños, y esos no quieren que [los] entierres. Es que todos volveremos a la tierra cuando termine el mundo, después, y los animales también van a buscar sus huesos en la selva, allí los vas a dejar. Cuando regresa [el espíritu del animal] allí va a buscar su esqueleto, en la cueva, en el árbol, porque, si no, ¿cómo le van a hacer? (don B., Nahá, 12 de enero de 2021).

En el apartado anterior y en el presente se mencionaron las reglas que determinan el tratamiento post mortem de los cuerpos: los humanos deben enterrarse, mientras que los restos de los animales deben depositarse en la selva. A continuación se presentarán las excepciones que permitirán reflexionar sobre la noción de "persona" en el grupo lacandón.

\section{Excepciones: "humanos" que no se entierran, los fetos y los productos}

En un trabajo concerniente a las concepciones lacandonas sobre los estados liminales mencioné que los Hach Winik no conciben los fetos como "humanos" (Balsanelli, 2019), pues se encuentran en una condición transitoria que parece oscilar entre la humanidad y la animalidad. Se trata de una concepción de larga difusión entre los pueblos nativos, según la cual el feto se describe como un ser dotado de una naturaleza ambigua y, por lo tanto, peligrosa (Eliade, 1974, p. 15; Lévi-Bruhl, 1974, pp. 33-34, 154; Platt, 2002). Mary Douglas argumenta que la peligrosidad atribuida a los fetos y al producto de los abortos se debe a su condición liminal, pues quedan atrapados en una especie de línea de demarcación entre un ser humano y "otro tipo de ser" (1973, p. 131).

Vilaça (2002) reitera que, en los grupos amazónicos, el parentesco no se sustenta sobre una base biológica, sino que debe construirse desde el momento de la concepción. En este sentido, el hecho de que un padre y una madre pertenezcan a la especie humana no garantiza que la criatura en el vientre materno sea también humana, pues posee una condición ontológica indefinida. Como se anticipó en la introducción, la persona indígena se construye a lo largo del tiempo, a medida que el niño o la niña crece y es introducido al mundo social. Algunos mayas contemporáneos comparten la misma idea, se piensa que el elemento dado es el alma, mientras que el cuerpo - lo que define y diferencia a cada grupo- debe construirse a través de determinadas prácticas culturales. En este contexto, los fetos suelen concebirse como pequeños retoños animales, los cuales deberán transformarse en personas, alimentándose de la comida de sus semejantes, aprendiendo el idioma y las costumbres, logrando, así, formar parte del grupo cultural de sus semejantes (Gossen, 1980, p. 46 y 1989, p. 44; Guiteras, 1965, p. 97; Pitarch, 2000, p. 7 y 2013, p. 29). Los lacandones no asignan un nombre al niño o niña en el vientre materno, lo hacen tres meses después del nacimiento. Durante ese periodo, se le refiere con el término chan och, "pequeño tlacuache"4 (Baer y Baer, 1950, pp. 185-186). Cuando un niño pregunta sobre su origen, la madre le explica que nació como un tlacuache, al cual ella le cortó la cola y que, con el tiempo, perdió sus garras y el vello, volviéndose así una persona (Balsanelli, 2019, pp. 18-19). Al igual que los lacandones, también los chamula se refieren a los niños utilizando el nombre de un animal (mono) y no le asignan un nombre propio; Gossen explica esta asociación, en cuanto a que el mono representa una antítesis de lo humano.

\footnotetext{
${ }^{4}$ Tlacuache, och en lengua maya [Didelphis virginiana].
} 
Cada vida humana se organiza en etapas por medio de ritos de pasaje en tiempo del nacimiento, del bautizo, del matrimonio y de la muerte. Desde el nacimiento hasta el bautizo (un mes a dos años), al niño se le llama mono (mash), pues no tiene nombre. Este homónimo se explica por el vínculo simbólico que tiene un niño sin bautizar con los monos que habitaban la tierra antes de salir por primera vez el Padre Sol para crear el mundo y la cultura humana. Los monos tenían costumbres bárbaras, como la de comer a sus propios hijos pequeños, a los que todavía no se les había puesto nombres, estando bien gordos éstos en la juventud (Gossen, 1989, p. 444).

Del mismo modo, entre los tsotsiles estudiados por Guiteras, el desarrollo del feto se concibe como la metamorfosis de un pequeño retoño animal en persona. Así lo explica la autora en la siguiente cita: "Se cree que el feto comienza a desarrollarse en forma de ratón. Empieza a crecer y un mes después es algo así como un sapo. Durante el tercer mes parece una criatura diminuta, con nariz, ojos y una boca que se abre" (Guiteras, 1965, p. 97).

Cuando una mujer lacandona tenía un aborto, el producto no se enterraba, sino que se depositaba en el tronco de un árbol. ${ }^{5}$ Esto lleva a suponer que la criatura no se consideraba "humana" porque murió antes de convertirse en un lacandón. Así, si la vida de la criatura se interrumpe antes de que dicho proceso llegue a su cumplimiento, queda atrapada en la condición de "animalidad" y es devuelta a los árboles, al dueño de los animales. Por el contrario, los niños que fallecen después de haber superado el segundo o tercer año de vida se entierran "como lacandones".

\section{Excepciones: animales que pueden enterrarse y animales que deben enterrarse}

En el presente apartado se mencionarán algunas excepciones observadas en el tratamiento de los cuerpos de los animales, pues en campo se destacó que algunos de ellos pueden ser enterrados y otros deben ser enterrados. En primer lugar, es necesario distinguir entre animales silvestres y domésticos. Los lacandones no poseen grandes rebaños - vacas, caballos, puercos - cuya crianza se torne incompatible con el ambiente de la selva y con las normas establecidas por el Área de Protección de Flora y Fauna. ${ }^{6}$ Así, las familias se limitan a criar aves de corral como pavos, patos y gallinas. Cuando se alimentan de la carne de estos animales, o de carne de res y de puerco adquirida en los ejidos colindantes, los huesos pueden ser quemados o dispersados al azar; si fallece un ave de corral por alguna enfermedad, su cuerpo también puede ser enterrado, ello, como ya se aclaró previamente, queda estrictamente prohibido en el caso de los animales silvestres.

A continuación, se ahondará en la razón que justifica esta diferencia de tratamiento, la cual puede notarse también analizando las ofrendas rituales destinadas para las deidades lacandonas. En el transcurso de ciertas ceremonias, los Hach Winik ofrendaban en los incensarios sagrados tamales ceremoniales, llamados nahwah, los cuales tenían que rellenarse con carne de animales de la selva, en particular, de

\footnotetext{
${ }^{5}$ En el grupo lacandón hay personas que aún llevan a cabo esta práctica si el aborto ocurre en casa. No obstante, el depósito en la selva se realiza en secreto. Recientemente, supe de una mujer que tuvo un aborto en un hospital y pidió a los médicos que se le entregara el producto para llevarlo a la selva.

${ }^{6}$ Las comunidades lacandonas en las que se realizó el presente estudio se encuentran hoy asentadas en el Área de Protección de Flora y Fauna Nahá-Metzabok, instituida por el gobierno mexicano en el año 1998.
} 


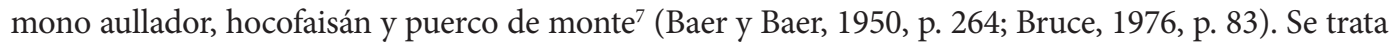
de ofrendas rituales sagradas destinadas a las deidades, como lo explica McGee, analizando el término nahwah compuesto por el sustantivo wah (tortilla) y el adjetivo nah (grande, sobrenatural). De este modo, el nahwah no es simplemente un tamal, sino "la comida de los dioses" (McGee, 1983, p. 121). En el pasado, rellenar los tamales ceremoniales con carne de pollo se consideraba un insulto hacia los dioses (datos de campo, Metzabok, 2021). Villa Rojas encuentra la misma diferenciación entre los mayas de Quintana Roo. En la descripción de las ofrendas rituales destinadas para los dueños (los yuntzilob) aclara lo siguiente:

Las ofrendas que corresponden a los yuntzilob son más especializadas y preparadas con mayor esmero; algunas de ellas se consideran tan sagradas e importantes que requieren ser preparadas por los hombres en la propia iglesia y de acuerdo con una técnica culinaria distinta de la usual. Además, se procura que la mayor parte de la carne usada en esta comida sea de animales silvestres como el venado, jabalí o pavo. La razón de esta preferencia se debe a que tales animales (criados por guardianes sobrenaturales y en contacto con los yuntzilob del monte) son considerados de mayor pureza que los criados por los hombres; es por ello que, en el lenguaje ceremonial se les llama "suhuy alakob", que es como decir "animales domésticos sagrados". Para obtener estos animales se organizan cacerías antes de cada ceremonia importante (Villa Rojas, 1992, p. 308).

Como puede notarse, los animales del monte son definidos como "domésticos y sagrados", en cuanto a que son criados por los dueños de la fauna y poseen una "pureza" de la cual los animales criados por los humanos están desprovistos. De hecho, Gabriel observa que los mayas yucatecos deben bendecir o purificar las aves de corral antes de ofrendarlas en los altares para despojarlas de su carácter profano. De acuerdo con la autora, este proceso "les concede el estatus de pertenencia a la naturaleza, como los ba'al che r-oob, los animales silvestres. Y con este estatus son equivalentes a los animales silvestres ofrendados en el ritual agrario" (Gabriel, 2018, p. 286).

En el grupo lacandón se define a los animales domésticos con el término -ärak si se trata de animales criados en hogares, y los designarán como u yärak winik (criados por la gente), mientras que, si se trata de animales silvestres, podrán referirse a ellos con las palabras u yärak k’uh (criados por las deidades) o u yärak u yum’il (animales domésticos de su dueño). La razón por la cual los restos de estas dos clases de animales no reciben el mismo trato parece obvia; una informante explicó lo siguiente: "Los pollos son míos, yo los crío, los alimento, no me enojo si mis hijos queman sus huesos, son de ellos también. Los animales de la selva no me pertenecen, no los alimento, le pertenecen a su dueño y ese sí se enoja" (doña Chosnuk, diario de campo).

Cuando se investiga sobre las concepciones inherentes a estos animales, los lacandones proporcionan respuestas contradictorias; la mayoría de los interlocutores e interlocutoras les atribuyen la posesión de alma, pues no se concibe la existencia de seres vivos desprovistos de pixan, no obstante, no se les otorga la condición de winik. Por lo general, para justificar lo anterior, los Hach Winik argumentan que esos

\footnotetext{
${ }^{7}$ Mono aullador, bats' en maya [Alouatta pigra]; hocofaisán, kambul en maya [Crax rubra]; cerdo de monte, kitám en maya [Tayassu tacaju].
} 
animales no fueron creados por los dioses lacandones, sino por el dios de los extranjeros (Ah Kyanto'), y que llegaron posteriormente a la selva; por ello, desconocen cuál es el destino final de su alma. Un hombre de Metzabok solucionó el dilema en los siguientes términos:

Tienen pixan [alma], eso sí, o no estarían vivos, pero a dónde van, eso lo has de saber tú, que son animales de tu gente, no de aquí. Dímelo tú, que yo solo te puedo hablar de los animales de la selva. Yo digo que [los animales domésticos] son solo para comer. Los compro o los crío, como la carne, yo los pago, yo los crío, yo soy el dueño, no tengo que conservar los huesos y si muere un pollo enfermo, lo puedo enterrar (don R., comunicación personal, Metzabok, 19 de enero de 2021).

A continuación, se considerarán otras excepciones, por ejemplo, los animales que deben inhumarse. El perro y el zopilote son considerados Hach Winik, pues se trataría de hombres o mujeres lacandones disfrazados, quienes en cualquier momento pueden despojarse de su piel o de su plumaje para revelar su verdadera apariencia. De hecho, a los perros se les entierra como a personas, acompañando los cuerpos con ofrendas de tortillas y carne, además, se encienden velas para alumbrar el tránsito de su alma en el inframundo. La idea de que el perro es considerado Hach Winik es reforzada por el castigo que le espera a quien mate a uno de esos animales, el cual coincide con la condena destinada a los asesinos. Sobre ello, Boremanse expresa lo siguiente: "Si un hombre mata a un perro será castigado en el inframundo después de su muerte, su alma se quemará enteramente en el fuego de Kisin y no saldrá jamás de allá. Se consumirá completamente, como si hubiese matado a un ser humano" (2006, p. 240).

De la misma manera, no está permitido cazar zopilotes y, si se mata uno de ellos por accidente, debe ser enterrado en la selva o, al menos, se debe cubrir su cuerpo con hojas y ramas. Boremanse aclara que "los zopilotes tienen apariencia humana cuando se deshacen de sus plumas, llevan una túnica y cultivan maíz" (1984, p. 235). En las culturas amerindias, en las que los animales se consideran dotados de una condición de persona latente (Viveiros, 1996), se encuentran numerosas referencias al hecho de que los animales y otras entidades - los espíritus, los dioses - pueden convertirse en seres humanos despojándose de su piel o sus plumas y poniéndose ropa humana (Riviére, 1994). De acuerdo con Riviére, este proceso de metamorfosis también puede llevarse a cabo para que el sujeto metamorfoseado pueda convertirse en depredador. En los mitos lacandones se hallan numerosas referencias acerca de esta concepción: las deidades terrenales poseen una túnica doble, que normalmente aparece como el sak nok (túnica blanca) de los Hach Winik; sin embargo, cuando desean comer carne humana, pueden voltear la túnica y esta se convierte en una piel de jaguar (Baer y Baer, 1950, pp. 254, 260). La deidad, transformada en un jaguar, podrá así cazar y consumir a su víctima. En otros casos, la transformación no tiene como finalidad la depredación: en el grupo lacandón se afirma que los zopilotes y los perros pueden quitarse sus plumas y su piel para cobrar apariencia humana, como se relata en dos mitos que hablan de dos hombres que desposaron a un zopilote y a un perro, ambos "convertidos en mujer" tras haberse quitado sus plumas y su piel, y haberse puesto un traje de mujer (Boremanse, 2006, pp. 237-240, 257-262).

En campo se registró otro animal que es considerado un lacandón atrapado en el cuerpo de un animal y que, por lo tanto, debe enterrarse. Se trata del armadillo, ${ }^{8}$ al cual se le llama u pixan winik (el alma de una

${ }^{8}$ Armadillo, wech en maya [Dasypus novemcintus]. 
persona), pues no se encuentran referencias sobre este en otras etnografías. Los informantes sostienen que se trata de un animal peculiar parecido a un armadillo (wech), pero, en realidad, es un lacandón que, tras haber cometido graves faltas, fue convertido en animal por los dioses. Según las personas entrevistadas, este puede distinguirse de un armadillo común porque presenta algunas características anómalas: "Le decimos u pixan winik o $u$ kisin winik (el demonio de la persona). Es armadillo, pero se ve que no es normal por sus ojos, son de winik, y sus manos no son como las de un wech [armadillo], son como de winik, tiene cinco dedos" (Bor G., comunicación personal, Nahá, 2 de enero de 2017).

Un hombre de Metzabok aclaró que, si por error se mata a uno de esos armadillos y se pone en el fuego para asarlo, su carne arde y sus huesos se deshacen. Sobre ello mencionó lo siguiente: "ves que sus huesos se vuelven como polvo, eso no es normal. Es que no puedes quemarlo, es persona, y allí te das cuenta de que has matado al wech equivocado" (don Kayum, comunicación personal, Metzabok, 19 de enero de 2021). En la entrevista que se presenta a continuación, doña Nuk aclaró que es necesario enterrar a ese animal en caso de matarlo por accidente.

Nuk: ¡Mixmok ku chik a wech, es que es winik ki! Es u pixän winik [Nadie come a ese armadillo, ¡es que es gente! Es el alma de una persona], cuando se muere la gente mala, se queda en la tierra, en ese animal. Es como de gente su mano y nadie come a ese wech. Su mano tiene cinco dedos. Alai Hach Winik! Y bek’a winik u jo' [¡Ese es un lacandón! y tiene cabeza de persona], también su cabeza parece de gente.

$[\ldots]$

A: Mảa häntik alai? [¿No se lo comen?].

Nuk: Mảa, mixmok ku häntik [No, nadie lo come].

A: Wä a kinsik, bai ka meetik yetel u bäkel? [Si lo matan, ¿qué hacen con su cuerpo?].

Nuk: Como es Hach Winik, tu mukah [Como es lacandón, se entierra].

El testimonio de Nuk permite aclarar que, al tratarse de un Hach Winik metamorfoseado, este peculiar tipo de armadillo no debe matarse y su carne no debe ser consumida, además, al morir debe enterrarse. Esto sugiere que su alma no le pertenece al dueño de los animales; en este caso, sus despojos serían depositados en los troncos de los árboles, al igual que las presas de cacería y los productos de los abortos.

\section{Reflexiones conclusivas}

Cada grupo humano necesita organizar la alteridad en categorías, un proceso que Descola define como "clasificación ontológica" (2012). Los métodos que rigen estas construcciones taxonómicas son culturalmente variables. En particular, este método de organización de lo existente se torna indispensable en los grupos que reconocen una condición común de todos los seres; en los casos en que todo es considerado "persona" y comparte la misma subjetividad, es necesario emplear otros métodos clasificatorios para marcar los límites y las diferencias (Vilaça, 2002). Se trata de un recurso conceptual que permite a cada grupo autodefinirse y diferenciarse de la alteridad y, además, regula el comportamiento de sus miembros hacia los demás grupos sociales.

De acuerdo con las concepciones lacandonas, cada criatura que mora en la selva está dotada de alma (pixan) y, por consiguiente, se le otorga una condición de humanidad latente, la cual se conceptualiza con el término winik (gente, persona). Ello consiste en la condición común de todos los seres que son iguales 
en esencia; en este sentido, el alma de un lacandón y la de un pecarí son idénticas; ambos son "gente" y se ven como personas al interior de sus grupos de pertenencia. Siendo el alma el elemento común, en el pueblo lacandón se clasifica la alteridad a partir de los cuerpos. Los humanos (los hombres y mujeres lacandones) son la Gente Verdadera, una connotación que adquiere significancia al interior del contexto social, y es una condición que se afirma a lo largo de la vida del sujeto, cuando el infante se separa del dominio del reino animal (el feto-tlacuache) para hacer su ingreso al mundo social a medida que se construye el cuerpo. En este caso, el término Hach Winik se emplea como etnónimo, el cual diferencia a los lacandones de la alteridad humana - las personas extranjeras y de los demás grupos indígenasy de la alteridad cósmica - las deidades, los animales, las plantas-. Todos son "gente", pero solo los lacandones son la "gente auténtica" (Boremanse, 2006, p. 138, notas 326 y 328). En el escrito se analizó la manera en la cual los Hach Winik destinan diferentes tratamientos a los restos de los distintos seres que abandonan el mundo terrenal; todos poseen el alma inmortal (pixan), por consiguiente, después de la muerte, tanto los humanos como los animales llegan a un destino final. Las almas de los seres humanos morarán en la cueva del dios de la lluvia Mensabäk, mientras que las de los animales silvestres habitarán los bosques del inframundo. En este contexto, la corporeidad que caracteriza cada ser es lo que determina el manejo de sus despojos; la regla general prescribe que todo Hach Winik (persona lacandona) debe enterrarse y recibir un rito funerario específico, el cual posibilita la llegada del alma al inframundo. Por el contrario, los restos de los animales silvestres deben devolverse a la selva, pues estos son pertenencias de los dueños o deidades que tutelan la fauna silvestre y acuática. A primera vista, lo que acabamos de ilustrar parece encajar en las clásicas dicotomías occidentales humanidad/animalidad, cultura/naturaleza, no obstante, el estudio de las excepciones mencionadas en la segunda parte del texto nos permitió esclarecer que los lacandones elaboraron una peculiar noción de persona, la cual se hace manifiesta en el tratamiento del cuerpo de algunas criaturas; algunos animales son considerados Hach Winik disfrazados - el perro, el zopilote, el armadillo pixan winik-y, por lo tanto, necesitan de un entierro. Queda claro que, de acuerdo con el grupo lacandón, los seres mencionados no pertenecen al reino animal, sino al ámbito de lo humano, mientras que, por lo contrario, los fetos o los bebés que fallecen durante los primeros meses de vida - los cuales en el pensamiento occidental se categorizan como seres humanos- se depositan en los árboles y son considerados criaturas silvestres que vuelven al corazón de la selva con sus legítimos dueños. Lo anterior atañe a la idea de que el cuerpo indígena no es una dotación biológica o dada, sino una condición adquirida al interior del contexto social a lo largo del desarrollo del niño o la niña.

Por su parte, los animales domésticos pertenecen a una categoría ambigua; los informantes no dudan en afirmar que estos poseen alma, no obstante, se trata de criaturas ajenas a la selva introducidas posteriormente, por lo tanto, sus restos no están sujetos a los mismos tratamientos y tabús destinados a la fauna silvestre. Además, vimos que los despojos de los distintos seres del cosmos son devueltos a las deidades que tutelan a cada grupo; los restos de los humanos se entierran para que el alma pueda llegar a las deidades del pueblo lacandón, mientras que los restos de los animales silvestres y acuáticos son recogidos por sus deidades o sus dueños en sus lugares de origen (las cuevas, los árboles, los lagos). Los dueños de los animales domésticos son los seres humanos, de este modo, ellos pueden enterrarlos, quemar sus huesos o dispersarlos al azar.

Se quiso demostrar que el estudio de las clasificaciones ontológicas de un grupo es imprescindible para esclarecer las nociones, los aspectos rituales y las instituciones sociales que este ha elaborado en 
el marco de su cosmovisión; en este caso, se analizó el tratamiento funerario de los distintos seres del cosmos, y se llegó a la conclusión de que los lacandones poseen una idea de persona que difiere de la idea occidental, y esto influye sobre la manera de tratar los cuerpos cuando las almas de los distintos seres abandonan el plano terrenal.

\section{Referencias}

Anderson, E. N., y Tzuc, M. F. (2005). Animals and the Maya in Southeast Mexico. University of Arizona Press.

Århem, K. (1996). The cosmic food web, Human-nature relatedness in the Northwest Amazon. En D. Philippe y G. Pálsson (eds.), Nature and Society (pp. 186-204). Routledge.

Baer, P., y Baer, M. (1950). Lacandon Ethnographic Materials, Microfilm Collection of Manuscripts on Middle American Cultural Anthropology, (XXXI). University of Chicago Library.

Baer, P., y Merrifeld, W. (1972). Los lacandones de México. Dos estudios. Instituto Nacional Indigenista, Secretaría de Educación Pública.

Balsanelli, A. (2019). De tlacuache a hombre: ideas sobre la gestación y la noción de persona entre los mayas lacandones de Chiapas, México. Boletín de Antropología, 34(57), 72-94.

Boremanse, D. (1984). Mitología y organización social entre los lacandones (hach winik) de la selva chiapaneca. Estudios de Cultura Maya, (XV), 225-249.

Boremanse, D. (1998a). Hach Winik. The Lacandon Maya of Chiapas, Southern Mexico. Institute of Mesoamerican Studies; The University at Albany.

Boremanse, D. (1998b). Representaciones metafóricas de los antiguos mayas en mitos y ritos religiosos lacandones. Journal de la Societé des Américanistes, 84(1), 201-209.

Boremanse, D. (2006). Cuentos y mitologías de los lacandones. Contribución al estudio de la tradición oral maya. Academia de Geografía e Historia de Guatemala.

Boremanse, D. (2020). Ruins, Caves, Godse Incense burners, Northern Lacandon Maya Myths and Rituals. The University of Utah Press.

Brown, L. A., y Emery, K. F. (2008). "Negotiations with the Animate Forest: Hunting Shrines in the Guatemalan Highlands". Journal of Archaeological Method and Theory, (15), 300-337.

Bruce, R., Robles, C., y Ramos. E. (1971). Los lacandones 2: Cosmovisión maya. Proyecto de Estudios Antropológicos del Sureste; Instituto Nacional de Antropología e Historia.

Bruce, R. (1974). El Libro de Chan Kin. Instituto Nacional de Antropología e Historia.

Bruce, R. (1976). Textos y dibujos: lacandones de Nahá. Instituto Nacional de Antropología e Historia.

Cayón, L. (2012). Gente que come gente: a propósito del canibalismo, la caza y la guerra en la Amazonía. Maguaré, 26(2), 19-49.

Dehouve, D. (2008). El venado, el maíz y el sacrificado. Diario de Campo, Cuadernos de Etnología, (4), 1-39.

Descola, P. (2012). Más allá de naturaleza y cultura. Amorrortu.

Douglas, M. (1973). Pureza y peligro, un análisis de los conceptos de contaminación y tabú. Siglo Veintiuno Editores.

Eliade, M. (1974). Tratado de historia de las religiones. Ediciones Cristiandad (original publicado en 1954).

Estrada, A.C. (2009). "Naturaleza, cultura eidentidad. Reflexiones desdela tradición oral maya contemporánea". Estudios de Cultura Maya, (XXXIV), 181-201.

Fitzsimmons, J. L. (2009). Death and the Classic Maya Kings. University of Texas Press.

Frazer, J. (1944). La rama dorada. Magia y religión. Fondo de Cultura Económica (original publicado en 1890).

Gabriel, M. (2018). Lo profano y lo sagrado, elementos distintivos entre la alimentación cotidiana y la ritual. En M. del R. Domínguez Carrasco et al. (eds.), Los investigadores de la cultura maya (pp. 273-292). Universidad Autónoma de Campeche.

Gossen, G. (1980). Los chamulas en el mundo del sol. Tiempo y espacio en una tradición oral maya. Instituto Nacional Indigenista.

Gossen, G. (1989). El tiempo en San Juan Chamula: imistificación o mitología viva? Mesoamérica, (18), 441-459.

Guiteras Holmes, C. (1965). Los peligros del alma, Visión del mundo de un tzotzil. Fondo de Cultura Económica.

Houston, S., Stuart, D., y Taube, K. (2006). The memory of the bones, Body, Being and Experience among the Classic Maya. University of Texas Press.

Kováč, M. (2016). Into the Underworld: Landscapes of Creation and Conceptions of the Afterlife in Mesoamerica. En J. Źrałka y C. Helmke (eds.), Contributions in New World Archaeology, 10 (pp. 43-54). Polish Academy of Arts and Sciences; Jagiellonian University. 
Lévi-Bruhl, L. (1974). El alma primitiva. Península.

Lot-Falck, É. (2018). I riti di caccia dei popoli siberiani. Adelphi (original publicado en 1953).

Marion Singer, M.-O. (1991). Los hombres de la selva: un estudio de tecnología cultural en un medio selvático. Instituto Nacional de Antropología e Historia.

Marion Singer, M.-O. (1999). El poder de las hijas de luna. Plaza y Valdés Editores.

McGee, R. J. (1983). Sacrifice and Cannibalism: an analysis of the Myth and ritual among the Lacandon Maya of Chiapas, México [tesis de doctorado, Rice University].

McGee, R. J. (1990). Life, Ritual, and Religion among the Lacandon Maya. Wadsworth Publishing Company.

Osorio-López D., Mariaca, R., Santos-Fita, D., Nazar, D.A., y Huicochea, L. (2017). Cacería y cosmovisión en una comunidad ayuuk en San José el Paraíso, Oaxaca, México. Etnobiologia, 15(3), 54-66.

Petrich, P. (2007). El espacio sagrado entre los mayas del lago Atitlán. Estudios de Cultura Maya, (XXIX), 141-153.

Pitarch, P. R. (2000). Almas y cuerpo en una tradición indiggena tzeltal. Archives de Sciences Sociales des Religions, (112), 1-18. https://doi.org/10.4000/assr.20245

Pitarch, P. R. (2013). La cara oculta del pliegue: ensayos de antropología indígena. Artes de México-Consejo Nacional para la Cultura y las Artes.

Platt, T. (2002). El feto agresivo. Parto, formación de la persona y mito-historia en los Andes. Estudios Atacameños, (22), 127-155.

Riviére, P. (1994). Wysinwyg in Amazonia. Jaso, 25(3), 255-262.

Roblero, M. (2008). La relación hombre-naturaleza entre los lacandones de Nahá, Ocosingo, Chiapas. Liminar. Estudios Sociales y Humanísticos, VI(1), 125-140.

Scherer, A. K. (2015). Mortuary Landscapes of the Classic Maya: Rituals of Body and Soul. University of Texas Press.

Soustelle, G. (1959). Observations sur la religion des Lacandons du Mexique meridional. Journal de la Société des Américanistes, (48), 141-196.

Soustelle, G. (1966). Collections Lacandons, Catalogues du Musée de L'Homme. Muséum National D'Historie Naturelle, Serie H, Amérique III.

Thompson, J. E. S. (1982). Historia y religión de los mayas. Siglo Veintiuno Editores.

Tozzer, A. (1907). A comparative study of the Mayas and the Lacandones. Mc. Millan Co.

Vilaça, A. (2002). Making kin out of others in Amazonia. Journal of the Royal Anthropological Institute, (8), 347-365.

Vilaça, A. (2014). Culture and Self. The Different 'Gifts' Amerindians Receive from Catholics and Evangelicals. Current Anthropology, 55(10), 322-332.

Villa Rojas, A. (1992). Los elegidos de Dios. Etnografía de los mayas de Quintana Roo. Instituto Nacional Indigenista.

Viveiros de Castro, E. (1996). Os Pronomes Cosmológicos e o Perspectivismo Ameríndio. Mana, 2(2), 115-144.

Viveiros de Castro, E. (2010). Metafísicas caníbales. Líneas de antropología postestructural. Katz Editores. 